Check for updates

Cite this as: $B M / 2021 ; 373: n 1070$ http://dx.doi.org/10.1136/bmi.n1070 Published: 05 May 2021

\section{Universal basic income and covid-19 pandemic}

This editorial by Salil B Patel and Joel Kariel (BMJ 2021;372:n193, doi:), incorrectly described a review cited as reference 16 (). The editorial stated: “A review of studies focusing on the effects of universal basic income on health, was published in 2020. Twenty seven studies reported health benefits, including reduced mortality, improved adult health, and increased provision of nutrients for low birthweight infants."

The first author of the review, Marcia Gibson, has pointed out that it included studies of interventions that were "similar to basic income," as reflected in its title. Secondly, although the review did include 27 studies, only 12 of these reported health outcomes, and several found null or negative effects. Both studies that reported effects on mortality found increases, which were linked to increased substance abuse. These negative effects come with substantial caveats, but the effects were far from exclusively positive. 